\title{
The Implicit and Explicit Motivations of Tourist Behaviour in Sharing Travel Photographs on Instagram: A Path and Cluster Analysis
}

\author{
Jennifer Daxböck, Maria Laura Dulbecco, Sintija Kursite ${ }^{(\bowtie)}$, \\ Tommy Kristoffer Nilsen, Andrada Diana Rus, Joanne Yu (D), \\ and Roman Egger (iD) \\ Salzburg University of Applied Sciences, \\ Urstein Süd 1, 5412 Puch Urstein, Salzburg, Austria \\ \{jdaxboeck. imte-m2018, 1dulbecco. imte-m2018, \\ skursite.imte-m2018, tnilsen. imte-m2018, \\ andradadiana. rus, cyu. imte-m2018, \\ roman.egger\}@fh-salzburg.ac.at
}

\begin{abstract}
Instagram has been an emerging platform for tourists to share their experiences and connect with other users in the multiphasic travel stages. Despite the huge number of photographs shared on Instagram on a daily basis, it remains ambiguous regarding the underlying motives of tourists' posting behaviour. Thus, this study aims to conceptualise a framework based on the internal and external triggers of sharing travel photographs through a mix methods design involving diary studies and questionnaires. By conducting a path analysis, this study presents and validates a theoretical model including various motivational factors; namely enjoyment, self-esteem, recognition, interests, social norms, goals, social ties, social status and prestige, selfefficiency, outcome expectations and memorabilia. Meanwhile, this research clusters young techsavvy tourists into four distinct segments based on their behaviour of using Instagram while traveling. By bridging motivational theories, social psychology, and social media in the context of tourism, this research extends literature related to user-generated content and Instagram. Practically, this research allows marketers to optimise the effectiveness of marketing strategies based on the characteristics of tourists and their behaviour on social media platforms.
\end{abstract}

Keywords: Motivation $\cdot$ Instagram $\cdot$ Posting behaviour $\cdot$ Tourism $\cdot$ Social media

\section{Introduction}

In the era of digitalisation, social media has not only transformed tourism marketing and management [1], but also drastically influenced tourist behaviour regarding how they share experiences and connect with one another [2]. In the multiphasic travel 
stages, the use of social media mediates the process of information search, decision making, experience co-creation, networking, and the creation of long-lasting memories $[3,4]$. Platforms commonly used by tourists are Facebook, YouTube, and Instagram. In particular, in quest of vivid content (e.g. pictures and videos) [5], Instagram has rapidly emerged as a trendy channel for tourists, especially the young tech-savvy generation, to share their travel experiences $[3,6]$. Comparing to other social media sites that are text intensive, pictures shared on Instagram create inspiration [7] and trigger potential tourists' imagination towards a destination [8]. This can be evidenced by several studies related to Instagram tourism published recently [7-9]. In a nutshell, existing literature has focused on the role of Instagram in the perceived and projected destination image [10,11], destination branding [9], tourists' perceptions and online reactions (e.g. likes and comment) [6], the effectiveness of visual content [8], and the influence on travel planning [10]. Instagram has been proved as an essential tool for tourists to express their experiences, in which, about $45 \%$ of users reported travel as their top interests on Instagram [12]. However, since the existing research often addressed Instagram from the perspectives of destination marketers, the antecedents of sharing photographs on Instagram remain ambiguous. Scholars also claim that the role of Instagram is in its infancy in the content of travel and tourism [6, 8, 9].

Due to the strong social presence and the growth of social media, sharing travel experiences online merits attention among scholars and practitioners [2, 13, 14]. Understanding the motivations behind one's posting behaviour is valuable in that it provides deeper insight on the social, cultural and environmental characteristics of travellers, and thereby offering marketers suggestions to improve their management and marketing strategies accordingly [15]. An earlier study categorises factors influencing users' online behaviour according to the type of content and the type of social media into individual action and personal cognition motivation, self-centred motivation and community-related motivation [16]. Other scholars suggest that consumers use social media to share experiences because of the need for higher social status [17, 18], entertainment [17], social interaction [16], belongingness [16], and documentation [19], among many others. Given that tourists are influenced by various implicit and explicit motives to use social media during trips, Instagram as the most popular site for travel posts [20] remains underexplored.

Seeing the potentials of Instagram in optimising strategic planning and tourism promotion, this cross-domain study brings together social psychology, motivational theories, and social media in tourism. The objectives of this research is (1) to develop a conceptual framework for the motivations of tech-savvy tourists to post on Instagram while travelling and (2) to categorise tourists into different segments according to their characteristics. Theoretically, this study contributes to the body of literature on Instagram and tourism, and extends the existing knowledge on consumer behaviour in the digital sphere. Practically, the current study provides insights for tourism marketers to evaluate and improve the effectiveness of marketing strategies based on tourists' internal and external motives of using Instagram. 


\section{Literature Review}

Motivations refer to one's enthusiasm for doing something [19], which can be classified into intrinsic and extrinsic triggers. The former suggests that the engagement of behaviours arises from within an individual, whereas the latter is driven by the motives to gain external rewards/avoid punishment [21]. Examples of intrinsic factors are enjoyment, emotional connection, self-identification, and self-expression. Extrinsic motivations include economic incentives, personal goals, and social networking.

Specific to Instagram-related literature, knowledge about others, selfdocumentation, coolness, and creativity are proved to be the most influential reasons for consumers to use Instagram [22]. Different from Facebook or Twitter, users often engage in the Instagram community to keep up with what their friends, family, or strangers are doing [22]. Another study takes the psychosocial factors into account, suggesting that enjoyment serves as a crucial factor for users to devote time to Instagram [23]. Other scholars claim that social media functions as a platform for consumers to present the best of themselves [24]. Accelerated by emerging visual-centered digital platforms, individuals can express and project different aspects of the self through photographs [24]. For instance, Eckhaus and Sheaffer [25] underpin that sharing content on social media improves the extent of self-esteem. Similarly, another research identifies selfexpression as one of the main factors of using Instagram [23].

Apart from individuals' self motives, tourists also share travel-related photographs in an attempt to gain social status and prestige [17,18]. Tourists could fulfil prestige by visiting destinations that impress their friends and family [26] or experiencing something others have not travelled to [27]. As social media features instantaneity by nature, tourists can already gain gratification and recognition even during the trip [18] by uploading photographs in real-time. This foreseeable reward thus fosters tourists' intentions to use Instagram while traveling. The uniqueness of each tourism experience implies that tourists can receive different kinds of social return from other online users [18] through liking, commenting, and sharing behaviour [6].

While investigating the fundamental motives to share experiences on social media has received tremendous interests, it appears that there is no general consensus among researchers. Some studies support the notion of external motivations [16, 28], while others argue that internal motives are the most influential drivers affecting user behaviour [17, 21, 23, 24, 29]. Therefore, driven by the sophistication of psychological, social, and environmental factors, the diversity of tourists' posting behaviour on Instagram during trips calls an urgent need to develop a holistic framework to better understand the underlying characteristics of tech-savvy tourists. The development of the conceptual model is explained in the following methodological sections.

\section{Methodology}

This research adopted a triangulation of a diary study and a survey method to identify tourists' motivations to post on Instagram during trips. Methodology consisted four steps: (1) conducting diary studies, (2) refining the conceptual model, (3) developing the survey and collecting data, (4) implementing path analysis and cluster analysis. 


\subsection{Step 1: Diary Study}

First, diary studies serve as the basis for developing the survey instruments. This technique is particularly suitable for research topics that have not been widely investigated [30] (e.g. users' motives to post on Instagram in the tourism domain). A convenience sampling technique was applied. With a particular interest on Instagram, the selection criteria was based on potential participants' activities on Instagram such as the frequency of sharing travel pictures and regular updating. Moreover, to guarantee effective memory retrieval, participants were required to have at least a one-week travel experience between July to September 2019. A pilot diary study was conducted first with three participants to minimise confusion and misunderstanding of the instructions. Eventually, ten individuals age between 18 to 28 were selected to participate the diary studies. Participants were asked to make a diary entry online whenever they posted a picture on Instagram while traveling.

\subsection{Step 2: Refinement}

Researchers manually read through each of the diary entries. The content was coded into various motivational factors based on literature, including enjoyment, selfesteem, social ties, recognition, interests, social norms, goals, self-efficacy and outcome expectations. Meanwhile, memorabilia was identified by the researchers as an additional trigger that is rarely mentioned by other scholars. In this case, memorabilia refers to the behaviour to share travel pictures for personal collection and storage of memories. These items hence served as the basis for the development of the survey.

\subsection{Step 3: Data Collection and Survey Development}

The questionnaire consisted three parts. The first section contained screening questions to ensure that the participants belong to the young tech-savvy generation. Specifically, this research took the notion of 'digital natives' [31], defined as the contemporary users of technologies born between 1977 and 1997. Additionally, participants inactive on Instagram during trips were excluded. The second section focused on the relationship between tourist behaviour in the context of sharing pictures on Instagram while traveling and the intrinsic and extrinsic factors. According to the identified motivations in step 2, this study summarised a list of 47 statements to measure 11 motives based on previous research $[16,17,32,33]$ (i.e., enjoyment, self-esteem, recognition, interests, social norms, goals, social ties, social status and prestige, selfefficiency, outcome expectations, and memorabilia). A 6-point Likert scale was adopted ( $1=$ strongly disagree; $6=$ strongly agree). The last section concerned with demographic information and participants' general usage of Instagram.

Note that this study did not rely on existing scales. Instead, measurements were based on previous literature and the results derived from the diary studies. To ensure the validity of the questionnaire, the scales were first assessed using Cronbach's alpha. Data collection was conducted in November 2019 through email invitations and social media sharing on Facebook and Instagram. No incentives were given. A total of 376 
young tech-savvy tourists completed the survey. Table 1 presents that the framework is reliable and has internal consistency.

Table 1. Cronbach's alpha results for questionnaire items.

\begin{tabular}{l|l|l}
\hline Motives & Cronbach's alpha & Number of items \\
\hline Goals & 0.606 & 4 \\
\hline Interests & 0.676 & 4 \\
\hline Social status and prestige & 0.686 & 4 \\
\hline Social norms & 0.748 & 4 \\
\hline Outcome expectations & 0.730 & 4 \\
\hline Self-efficacy & 0.729 & 5 \\
\hline Memorabilia & 0.829 & 4 \\
\hline Enjoyment & 0.857 & 4 \\
\hline Recognition & 0.636 & 4 \\
\hline Self-esteem & 0.678 & 6 \\
\hline Social ties & 0.552 & 4 \\
\hline
\end{tabular}

\subsection{Step 4: Data Analysis}

This research first presents the participants' demographic background and their behaviour of using Instagram and posting pictures during trips. Next, to investigate the causal connections between variables to refine the proposed conceptual framework, path analysis was implemented to assess the relationship between the motivations to post on Instagram while travelling and the observed motivational factors.

A hierarchical cluster analysis was implemented to identify distinct traveller segments based on the 11 types of motivations to publish content on Instagram while travelling. The technique is particularly suitable for this study because it does not require one to pre-set the groups. Cophenetic correlation was calculated to identify optimal linkage. Next, Python was adopted to analyse the silhouette scores and Calinski-Harabasz index to determine a cluster solution in terms of interpretability, explanatory power and parsimony. A dendrogram was first generated from the whole sample. ANOVA was applied to examine whether the means of established clusters are significantly different from each other. The mean values of motivational factors were compared for all clusters. Finally, four types of tourists were identified based on their motives to post on Instagram during trips.

\section{Results}

\subsection{Demographic Profile}

A total of 376 digital natives $($ male $=32.7 \%$; female $=66.5 \%$; other $=0.8 \%$ ) participated in the study. Regarding their age, $76.6 \%$ are under the group of 18-24, $22.1 \%$ belong to $25-34$, and $1.3 \%$ are over 34 . The participants are composed mainly by 
Austrian (62\%) and German (15\%), followed by Norwegian (3\%), and Romanian $(2 \%)$, among others. Most of the respondents have been using Instagram for more than 3 years $(67.3 \%)$, followed by 2 to 3 years $(16.5 \%), 1$ to 2 years $(11.4 \%)$, and less than one year $(4.8 \%)$. They mainly post monthly (44.7\%), few times per month $(27.4 \%)$, weekly $(16.2 \%)$, few times per week $(5.9 \%)$, or daily $(4.5 \%)$. With regards to the indicated importance of posting on Instagram, $77.2 \%$ of travellers indicate that posting on Instagram is either somewhat important or important. Moreover, most people post photos either frequently $(28.7 \%)$ or occasionally $(46.8 \%) .10 .1 \%$ indicate that they always post, while $14.3 \%$ of participants rarely post on Instagram. It is noticeable that the majority of travellers post on Instagram at the end of the day $(61.4 \%)$, followed by those who post at the end of their trip $(26.1 \%)$. Just $12.5 \%$ of respondents post their experience immediately after taking the photo.

\subsection{Motivation to Post on Instagram While Travelling}

A descriptive analysis of the observable variables was performed, before going into details with the path analysis. It turned out that interest, followed by memorabilia and self-efficacy are the most important factors to post on Instagram. The lowest valued items were social norms, recognition, outcome expectations and prestige. Thus, it becomes clear that travellers have very complex reasons to post on Instagram and the traditional large bundles of motivation (e.g. egocentric motivations, narcissism, community-related motivations, individual action and personal cognition) are decisive. Hence, each of these factors consists of a diverse set of variables that have various influences on the overall motivation to post on Instagram while travelling.

\subsection{Path Analysis}

Path analysis was used to determine the correlations between motivational factors and the actual motivation to post on Instagram while travelling. The model was tested using a covariance matrix and maximum likelihood estimation (Fig. 1).

The latent variable "Motivation to post on Instagram while traveling" should be explained with the following observed variables: enjoyment, self-esteem, social ties, recognition, social status and prestige, interests, social norms, goals, self-efficacy, outcome expectations and memorabilia. The developed model indicates that all variables have a significant influence on the motivation to post on Instagram while travelling. Ultimately, it was found that the variable interests precedes the variables enjoyment, social ties and memorabilia, and thus a better model fit could be achieved for the final model. The factor of memorabilia influences the outcome expectations which further influences self-efficacy.

According to Fig. 1, all relationships are significant at a significance level of $\mathrm{p}$ 0.001 . Only between memorabilia and overall satisfaction there is no significant correlation. Several indices were used for the model fit. The Goodness of fit index (GFI) showed a good model fit with a value of .871. The values for normed fit index (NFI) and comparative fit index (CFI) were .88 and .89 respectively, indicating an acceptable fit to the data. The Root Mean Square Error of Approximation (RMSEA) 
value was too high with .129 , which however could be explained by both, the relatively sample size and the model size [34].

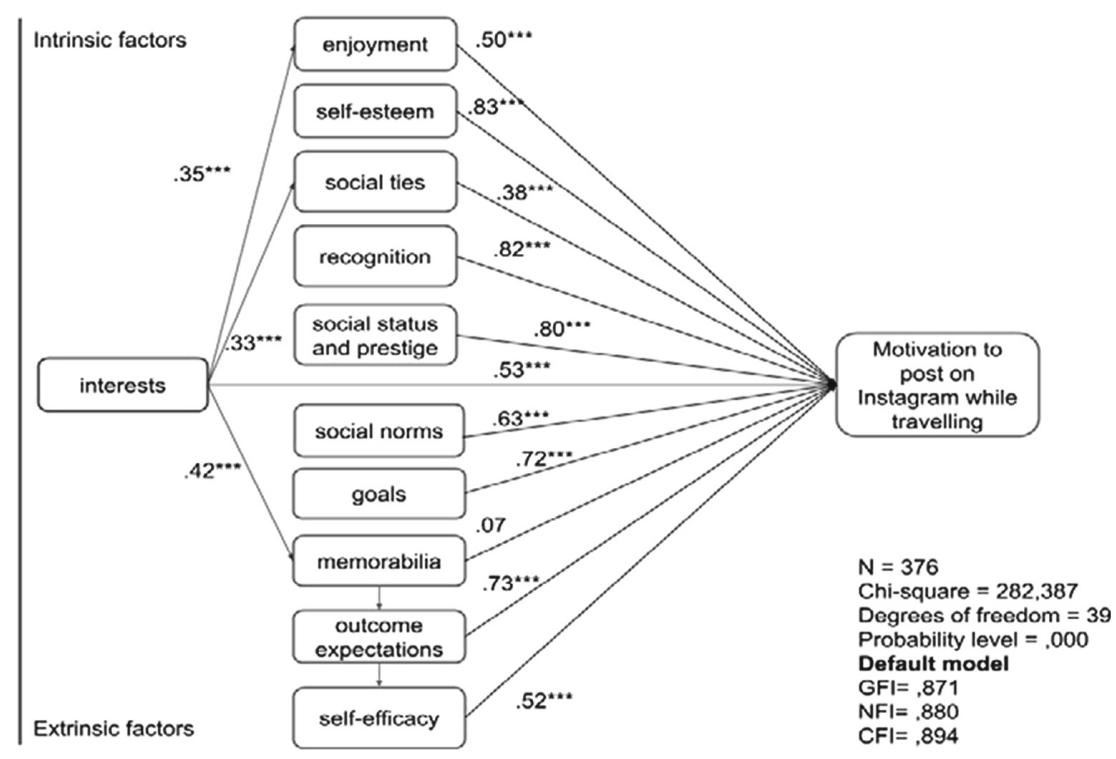

Fig. 1. Correlations between observed variables and the motivation to post on Instagram.

\subsection{Cluster Analysis}

Finally, a hierarchical cluster analysis was carried out to segment the travellers into ideal-typical, homogeneous groups according to their Instagram usage behaviour. The validation was conducted using the cophenetic correlation, in which, the average linkage method $(0.58)$ outperformed the values of single linkage $(0.37)$, complete linkage (0.48), and Ward (0.47). Next, based on average linkage method, silhouette scores were analysed in Python and presented a four-cluster solution (Table 2). The four-cluster solution was then evidenced by Calinski-Harabasz index (Fig. 2).

Table 2. Initial selection of cluster number based on silhouette scores.

\begin{tabular}{l|l|l|l|l|l|l|l|l}
\hline No. of cluster & 3 & $\mathbf{4}$ & 5 & 6 & 7 & 8 & 9 & 10 \\
\hline Scores & 21.57 & $\mathbf{6 5 . 0 5}$ & 49.57 & 46.26 & 41.00 & 36.41 & 41.63 & 37.76 \\
\hline
\end{tabular}




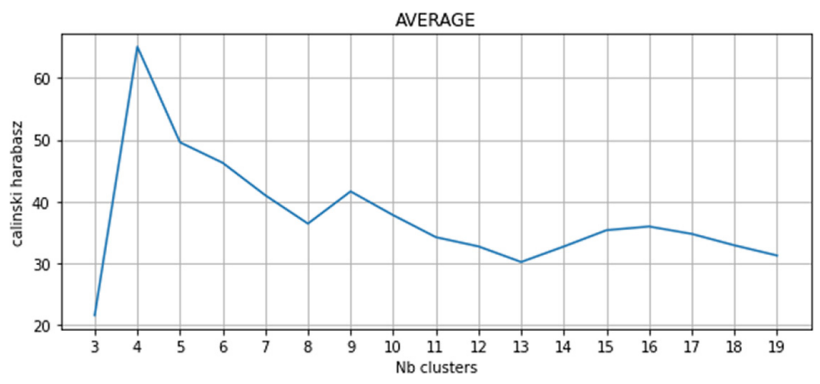

Fig. 2. Calinski-Harabasz index.

These four clusters are named as "The Charming Adventurer", "The Silent Spectator", "The Photo Collector" and "The Immersed Creator". ANOVA analysis found significant differences between all clusters regarding the constructs. It is important to note that in general the scores of interest, memorabilia and self-efficacy are among the highest for all clusters, which means that those are the most common influential factors for motivation to post on Instagram while travelling.

The Charming Adventure: The largest cluster, with 156 participants is characterised by a relatively high interest value (mean of 4.6) but rather low scores on prestige, recognition and social norms (means between 1.9 and 3.1). They post photos for enjoyment (mean of 4.08) and memorabilia (mean of 4.77). Their motivations are more intrinsically than extrinsically oriented. Instagram is of high importance for members of this group. People in this cluster have used Instagram on average since 2 to 3 years and open the app multiple times per day. They tend to post a lot while travelling and Instagram is a way for them to establish social ties.

The Silent Spectator: With 99 participants, this cluster represents the secondlargest group. People in this cluster score moderately high on community-related aspects such as prestige and social norms, and rather high on individual action and personal cognition scores (means between 2.5 and 3.6). Self-efficacy and outcomes are important for this group. Although they do not post regularly, Instagram is a must for members of this cluster. They are more active especially when traveling.

The Photo Collector: This cluster (73 respondents) contains the most passive Instagram users. These travellers consider that posting on Instagram while travelling is not that important (mean of 2.67 compared to 3.16 and higher for the other clusters). Members of this cluster tend to post for themselves, for memorabilia reasons (mean of 3.36 - highest value compared to the other clusters), outcome expectations or selfefficacy. They use Instagram regularly and many times per day but post much less while travelling than other groups.

The Immersed Creator: The smallest cluster, with 48 participants, shows the highest scores on all categories. These travellers use Instagram the most out of all the clusters (mean of 2.48 compared to 2.28 in Cluster 1, 2.09 in Cluster 2 and only 1.89 in Cluster 4). They are very active Instagram users and have been using the app for 2 to 3 years. 
They consider memorabilia, interests, and enjoyment as the main drivers to share pictures on Instagram during trips. They are posting the most while travelling and they think that posting on Instagram is moderately important to them.

\section{Conclusion}

As motivations are the primary drivers of purchase decisions, it is critical for tourism providers to understand tourists' physiological and psychological needs and wants in order to refine their marketing strategies. Seeing the power of user-generated content, investigating users' motivations to post on social media has been an emerging topic within the academia [22-24]. With a particular focus on Instagram, although recent research has attempted to bridge Instagram to tourism [7-9], the internal and external motives for young tourists to post on Instagram during trips are underexplored.

The current research thus presents a motivational framework and classifies tourists into four distinct segments. In line with previous literature [17, 21, 23, 29, 32], this study affirms that enjoyment, self-esteem, social ties, recognition, interests, social norms, goals, self-efficacy, outcome expectations and prestige, are related with users' motivations to post on Instagram while travelling. Notably, in addition to the fact that users would like to elevate their status and gain prestige by sharing on social media sites $[25,35]$, this study uncovers other factors that are more internal and self-centred such as recognition, enjoyment and self-esteem. This result can be interpreted from the nature of Instagram which focuses on visual content. Unlike other platforms such as Twitter and Facebook, Instagram functions as a social media site for individuals to present the best of themselves through photographs [24]. Furthermore, different from Facebook featuring a closed-knit community of people know each other, Instagram allows users to build and join communities according to their own interests. Thus, Instagram potentially decreases one's intention to be recognised within his or her social network. In the case of travelling, self-efficacy and outcome expectations are found to be more influential on affecting users' motivations to share on Instagram. In addition to the factors commonly mentioned by previous studies, the current research is novel in that it reveals 'memorabilia' as another crucial motive for tourists to post pictures on Instagram, which has never been mentioned in previous motivational research. Nevertheless, this finding is somehow in line with some recent studies, suggesting that taking photographs function as a way to create personal collections of memories [36, 37].

Moreover, this research proposes charming adventurers, silent spectators, photo collectors and immersed creators as the dominant tourist segments when sharing travel experiences on Instagram. First, charming adventurers mainly post for their own benefit and enjoyment but not for the sake of community relations. This contradicts to the study of van Dijk [38], where social ties are not directly linked to external motives. Instead, the current research discovers that social ties affect trust and recognition, and thereby leading to individual motivations and behaviours. As for silent spectators, members of this cluster also tend to be more influenced by the community's norms and are expecting a certain outcome from the posts they share while travelling. Next, photo collectors are considered as the most passive tourists on Instagram because their main motivations are to post for themselves for the purpose of saving memories. Though, 
'memorabilia' is in fact similar to souvenirs. It is well-known that tourists have impulse to commemorate their experiences by purchasing souvenirs [39]. With improvements in technologies, souvenirs can be presented in the form of visual narratives. A recent study suggests that by analysing memorabilia, marketers can understand more on tourists' preferences and psychological needs in order to facilitate the creation of meaningful travel experiences [40]. Lastly, immersed creators share pictures not only for their own benefits but also for the community. Storing memories and reflecting on their interests are the most important motives for them, followed by enjoyment.

On the whole, this study extends the existing knowledge on Instagram and tourism by conceptualising an Instagram motivational framework concerning with users' posting behaviour. Specifically, first, this research goes beyond travel experiences that have been often investigated by recent studies. Meanwhile, unlike most of the literature that considers young travellers as the same group of Instagram users, this study clusters digital natives based on their characteristics of Instagram usage. By looking at the intersections of social psychology, motivational theories, and social media in the context of tourism, this research highlights the significance in incorporating tourists' behaviour as well as their internal and external motives of using Instagram in the era of digitalisation. Practically, by understanding tourists' motivations, marketers and tourism-related businesses can improve their media communication and marketing techniques accordingly to boost tourists' intentions to share photographs on Instagram in the multiphasic travel stages. Finally, marketers are recommended to develop various strategies based on digital natives' characteristics to maximise the effectiveness of communication strategies through Instagram.

Nonetheless, the current research is not without limitations. First, this research implemented a convenient sampling method, in which, the participants are dominated by Austrian and German. Readers should bear in mind the potential cultural differences between users on Instagram on different continents. Furthermore, given that this is the first study to propose a motivational framework for Instagram travellers concerning with their posting behaviour, future research is recommended to further validate the results due to the infancy of the study context. On a broader marketing discipline focusing on social media, future studies are suggested to investigate whether the proposed model can be adopted in other similar social media sites such as Pinterest. Lastly, this research reinforces memorabilia as an emerging but underexplored field in studies related to user-generated content. Scholars are thus encouraged to continue this line of research in various digital context such as YouTube, Facebook, and online travel review platforms.

\section{References}

1. Lu Y, Chen Z, Law R (2018) Mapping the progress of social media research in hospitality and tourism management from 2004 to 2014. J Travel Tour Mark 35:102-118

2. Wang S, Kirillova K, Lehto X (2017) Travelers' food experience sharing on social network sites. J Travel Tour Mark 34:680-693

3. Varkaris E, Neuhofer B (2017) The influence of social media on the consumers' hotel decision journey. JHTT 8:101-118 
4. Camilleri J, Neuhofer B (2017) Value co-creation and co-destruction in the Airbnb sharing economy. Int J Contemp Hosp Manag 29:2322-2340

5. Urry J, Larsen J (2011) The tourist gaze 3.0, 3rd revised edn. Published in Association with Theory, Culture \& Society. SAGE Publications, London

6. Yu CE, Sun R (2019) The role of Instagram in the UNESCO's creative city of gastronomy: a case study of Macau. Tour Manag 75:257-268

7. Barbe D, Neuburger L, Pennington-Gray L (2020) Follow us on Instagram! Understanding the driving force behind following travel accounts on Instagram. E-Review Tour Res 17:1-8

8. Yu CE, Xie SY, Wen J (2020) Coloring the destination: the role of color psychology on Instagram. Tour Manag 80:104110

9. Fatanti MN, Suyadnya IW (2015) Beyond user gaze: how Instagram creates tourism destination brand? Procedia - Soc Behav Sci 211:1089-1095

10. Kuhzady S, Ghasemi V (2019) Pictorial analysis of the projected destination image: Portugal on Instagram. Tour Anal 24:43-54

11. i Agustí DP (2018) Characterizing the location of tourist images in cities. Differences in user-generated images (Instagram), official tourist brochures and travel guides. Ann Tour Res 73:103-115

12. Iqbal M (2020) Instagram Revenue and Usage Statistics (2020). https://www. businessofapps.com/data/instagram-statistics/. Accessed 19 Aug 2020

13. McMullen M (2019) 'Pinning' tourist photographs: analyzing the photographs shared on Pinterest of heritage tourist destinations. Curr Issues Tour 15:1-2

14. Buonincontri P, Morvillo A, Okumus F et al (2017) Managing the experience co-creation process in tourism destinations: empirical findings from Naples. Tour Manag 62:264-277

15. Oliveira T, Araujo B, Tam C (2020) Why do people share their travel experiences on social media? Tour Manag 78:104041

16. Munar AM, Jacobsen JKS (2014) Motivations for sharing tourism experiences through social media. Tour Manag 43:46-54

17. Bradley P (2015) Instagram: why do we post? Master thesis, Southern Illinois University

18. Boley BB, Jordan EJ, Kline C et al (2018) Social return and intent to travel. Tour Manag 64:119-128

19. Ghaisani AP, Handayani PW, Munajat Q (2017) Users' motivation in sharing information on social media. Procedia Comput Sci 124:530-535

20. Siegel LA, Wang D (2019) Keeping up with the joneses: emergence of travel as a form of social comparison among millennials. J Travel Tour Mark 36:159-175

21. de Vries L, Peluso AM, Romani S et al (2017) Explaining consumer brand-related activities on social media: an investigation of the different roles of self-expression and socializing motivations. Comput Hum Behav 75:272-282

22. Sheldon P, Bryant K (2016) Instagram: motives for its use and relationship to narcissism and contextual age. Comput Hum Behav 58:89-97

23. Alhabash S, Ma M (2017) A tale of four platforms: motivations and uses of Facebook, Twitter, Instagram, and Snapchat among college students? Soc Media + Soc 3:205630511769154

24. Choi TR, Sung Y (2018) Instagram versus Snapchat: self-expression and privacy concern on social media. Telematics Inform 35:2289-2298

25. Eckhaus E, Sheaffer Z (2019) Factors affecting willingness to contribute goods and services on social media. Soc Sci J 56:390-400

26. Al-Haj Mohammad BAM, Mat Som AP (2010) An analysis of push and pull travel motivations of foreign tourists to Jordan. Int J Bus Manag 5:41-50

27. Ying T, Wen J (2019) Exploring the male Chinese tourists' motivation for commercial sex when travelling overseas: scale construction and validation. Tour Manag 70:479-490 
28. Johnson TJ, Kaye BK (2015) Reasons to believe: influence of credibility on motivations for using social networks. Comput Hum Behav 50:544-555

29. Bell BT (2019) "You take fifty photos, delete forty nine and use one": a qualitative study of adolescent image-sharing practices on social media. Int J Child-Comput Interact 20:64-71

30. Bryman A (2016) Social research methods. Oxford University Press, Oxford

31. Judd T (2018) The rise and fall (?) of the digital natives. Australas J Educ Technol 34:99119

32. Borges-Tiago MT, Tiago F, Cosme C (2019) Exploring users' motivations to participate in viral communication on social media. J Bus Res 101:574-582

33. Decrop A, Woodside AG (2017) Buying, behaving, and being: a portrait of contemporary tourists. Adv Cult Tour Hosp Res 13:xv-xix

34. Gao C, Shi D, Maydeu-Olivares A (2020) Estimating the maximum likelihood root mean square error of approximation (RMSEA) with non-normal data: a monte-carlo study. Struct Equ Model Multidisciplinary J 27:192-201

35. Park H, Seo S, Kandampully J (2016) Why post on social networking sites (SNS)? Examining motives for visiting and sharing pilgrimage experiences on SNS. J Vacat Mark 22:307-319

36. Zhao Z, Zhu M, Hao X (2018) Share the gaze : representation of destination image on the Chinese social platform WeChat moments. J Travel Tour Mark 35:726-739

37. Tung VWS, Lin P, Qiu Zhang $\mathrm{H}$ et al (2017) A framework of memory management and tourism experiences. J Travel Tour Mark 34:853-866

38. van Dijk TA (1998) Ideology: a multidisciplinary approach. SAGE Publications, Thousand Oaks

39. Ferdinand N, Williams NL (2010) Tourism memorabilia and the tourism experience. In: The tourism and leisure experience. Consumer and managerial perspectives, pp 202-217

40. Wan CB, Chow KK, de Bont CJ et al (2020) Finding synergy between oral and visual narratives on memorable and meaningful tourism experiences. Inf Technol Tour 22:107-130

Open Access This chapter is licensed under the terms of the Creative Commons Attribution 4.0 International License (http://creativecommons.org/licenses/by/4.0/), which permits use, sharing, adaptation, distribution and reproduction in any medium or format, as long as you give appropriate credit to the original author(s) and the source, provide a link to the Creative Commons license and indicate if changes were made.

The images or other third party material in this chapter are included in the chapter's Creative Commons license, unless indicated otherwise in a credit line to the material. If material is not included in the chapter's Creative Commons license and your intended use is not permitted by statutory regulation or exceeds the permitted use, you will need to obtain permission directly from the copyright holder.

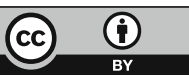

